Article

\title{
Determinants and Mechanisms of Tourists' Environmentally Responsible Behavior: Applying and Extending the Value-Identity-Personal Norm Model in China
}

\author{
Yongxun $\mathrm{Xu}{ }^{1,2}\left(\mathbb{D}\right.$, Xuechao Wei ${ }^{3}$ and Shih-Chih Chen ${ }^{4, *}$ (D) \\ 1 Department of Marketing, Business School of Jilin University, Changchun 130012, China \\ 2 Department of Marketing, School of Business Administration, Xuzhou Vocational College of Industrial \\ Technology, Xuzhou 221140, China \\ 3 Department of International Education, School of International Education, Xuzhou Vocational College of \\ Industrial Technology, Xuzhou 221140, China \\ 4 Department of Information Management, National Kaohsiung University of Science and Technology, \\ Kaohsiung 824, Taiwan \\ * Correspondence: scchen@nkust.edu.tw
}

Received: 30 May 2019; Accepted: 3 July 2019; Published: 6 July 2019

\begin{abstract}
It is well recognized that tourists' environmentally responsible behavior is a prominent contributor to the sustainable development of tourist destinations. Based on the original Value-Identity-Personal norm (VIP) model and self-efficacy theory, this study proposes an extended VIP model for exploring the generalized determinants of tourists' environmentally responsible behavior and investigating the impact mechanism of this behavior in China. A total number of 435 self-reported questionnaires were collected on a professional online survey platform. Our research results indicated that the extended VIP model could significantly and validly explain tourists' environmentally responsible behavior. Specifically, biospheric values have an indirect but rooted effect on tourists' environmentally responsible behavior. Furthermore, two indirect paths play the same mediational role between biospheric values and tourists' environmentally responsible behavior. The findings expand the application field of the VIP model, contribute to a better understanding for academic researchers of tourists' environmentally responsible behavior and shed light on managerial implications for practitioners in the sustainable development of tourist destinations.
\end{abstract}

Keywords: biospheric values; environmental self-identity; environmental self-efficacy; personal norm; tourists' environmentally responsible behavior; China

\section{Introduction}

With the sustained and steady development of the economy in recent years, tourism has experienced rapid growth in China. In 2018, the Chinese tourism industry contributed a total of 9.94 trillion Renminbi to GDP, directly and indirectly promoted 79.91 million in employment, and notably, Chinese tourists made 5.539 billion domestic trips [1]. Although a large number of tourists have promoted the economic development and population employment of tourist destinations, they have also brought about negative impacts on the environment of tourist destinations (e.g., discarding litter at will, collecting flora and fauna specimens, and arbitrarily inscribing and carving). The environment (including natural, cultural, and historical resources) is an important factor to promote the development of tourism, and is an indispensable contribution to the attractiveness and desirability of tourist destinations [2]. Therefore, how to achieve the sustainable development of tourist destinations has become an urgent problem for China. 
Facing the dilemma of the conservation of environmental resources between economic development and sustainable tourism, government authorities and tourist destination managers have often adopted regulatory measures such as restricting the scale of tourists, controlling tourists' behaviors, and funding the protection of environmental resources through tourism income. However, the appropriateness and effectiveness of these initiatives have been questioned by academic researchers [3]. For instance, some scholars suggest that regulatory measures come at the expense of tourism income and tourist experiences to realize sustainable tourism, and it is also extremely difficult to correct the inappropriate behavior of tourist $[4,5]$. Traditional management and regulation strategies essentially presuppose that tourists have negative impacts on the environmental resources of tourist destinations [6]. Nevertheless, many findings indicate that tourists have proactive environmental friendly behaviors during their trips, such as picking up their own litter [7], protecting rare flora and fauna, conserving historic and cultural buildings and statues [8], and volunteering and donating for the sustainable development of tourism destinations $[9,10]$. These behaviors of tourists are also referred to as Tourists' Environmentally Responsible Behaviors (TERB), which have been described as minimizing environmentally unfriendly activities and displaying a willingness to protect the environment in the context of a tour by Lee, Jan, and Yang [11]. The researchers deemed that TERB are critical for the sustainable development of tourist destinations $[8,11,12]$, and that cultivating and guiding TERB can greatly reduce the costs of protecting the environmental resources of tourist destinations [4], thereby coping with the dilemma of the environment in sustainable tourism. Hence, exploring the reasons and mechanisms of TERB has become an important concern for academic researchers.

Previous studies on the reasons for TERB were mainly divided into three aspects: the tourists' demographic characteristics (including gender, age, education, and income) [13-16], the tourists' psychological cognitive and emotional factors (e.g., environmental knowledge, environmental commitment, environmental sensitivity, place attachment, and travel experience) [8,16-20], and situational factors (e.g., social and subjective norms) $[7,21,22]$. Besides, several theoretical frameworks, such as the theory of reasoned action (TRA) [23,24], the theory of planned behavior (TPB) $[7,21,25]$, the norm activation model (NAM) [22,26], and the value-belief-norm (VBN) theory $[27,28]$, have been used to understand the mechanisms of TERB. Although these studies contribute to the understanding of the causes and mechanisms of the formation of TERB, little research has been conducted in the Chinese context. Furthermore, the results of these studies also have some limitations. For instance, the TPB only explained 25\%-30\% variance of a specific behavior [29], and the predictive validity of the VBN theory was weaker when the environmentally responsible behavior was more costly [30]. Therefore, the Value-Identity-Personal norm (VIP) model was proposed based on the VBN theory [31] and was used to significantly examine employees in the organizational context [32]. However, the VIP model has not been empirically tested on TERB, especially in the Chinese context.

To fill these research gaps, the extended VIP model (see Figure 1) is proposed to assess the effects of antecedents and mechanisms on TERB. The three main aims of this study are the following: (1) verifying the validity of the VIP model on TERB in the Chinese context; (2) adding Environmental Self-Efficacy (ESE) to the VIP model and testing the predictive ability of the extended VIP model; and (3) analyzing the formation mechanism of TERB and comparing the mediation effects of two indirect paths. The findings could expand the application field of the VIP model, increase the understanding of TERB, and provide effective and efficient management suggestions to practitioners in the sustainable development of tourist destinations.

The framework of the study was organized as follows: firstly, the researchers conducted a review of the original and extended VIP model and proposed the theoretical hypotheses; secondly, the methodology was presented, including measurement instruments, data collection processes, and statistical analysis methods; thirdly, we performed the data analysis; next, we discussed the results of the analysis; and finally, we provided the conclusions, academic contributions, managerial implications, and future research suggestions. 


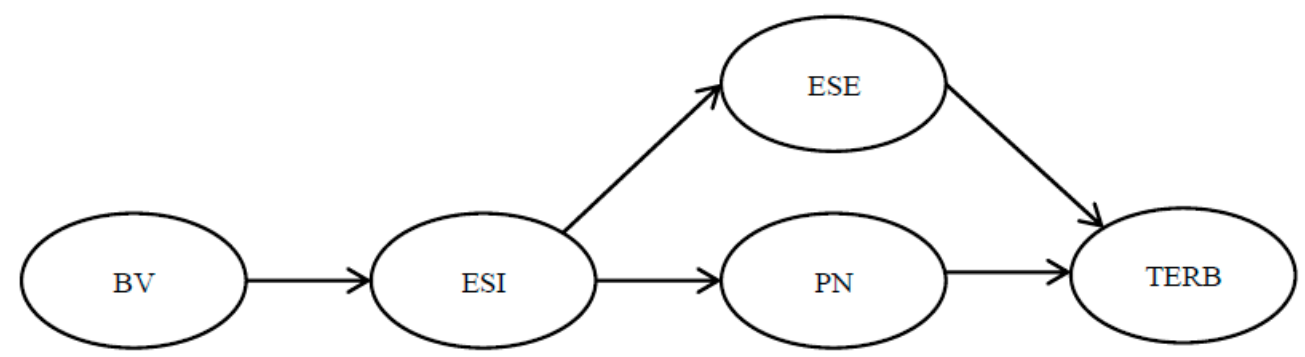

Notes: BV $=$ Biospheric Values, ESI $=$ Environmental Self-Identity, PN $=$ Personal Norm, ESE $=$ Environmental Self-Efficacy, TERB = Tourists' Environmentally Responsible Behavior.

Figure 1. The extended VIP model.

\section{Literature Review and Hypotheses}

\subsection{The Value-Identity-Personal Norm (VIP) Model}

The Value-Identity-Personal norm (VIP) model was originally proposed by van der Werff and Steg based on the VBN theory [31]. Compared with the VBN theory (integrating the value theory, the New Environmental Paradigm, and the norm activation theory into a causal chain) [30], the VIP model has two main differences: on the one hand, the causal chain of the VIP model is more general and simple than that of the VBN model; on the other hand, the VIP model pays close attention to general considerations of eco-friendly behavior [31]. The VIP model comprised three constructs in explicating the formed mechanism of TERB, namely biospheric values (BV), environmental self-identity (ESI), and personal norm (PN). This model assumes that individuals' general environmental considerations (including BV and ESI) have a rooted but indirect effect on their environmentally responsible behaviors [31]. Specifically, the BV, reflecting tourists' determination to perform TERB based on the welfare of the biosphere [33], could increase tourists' ESI. Next, the ESI, describing the extent to which a tourist considers himself/herself to be an environmentally responsible person [34], could strengthen tourists' PN. Finally, the PN, representing tourists' feelings of moral obligation to engage in environmentally friendly behavior [35], could motivate tourists to carry out TERB.

Before the VIP model was proposed as a whole, several researchers had already found that portions of the VIP model were significant and valid in explaining environmentally friendly behavior. For example, some findings found that one's ESI could mediate the relationship between BV and eco-friendly consumer behaviors (e.g., green energy behaviors, the preferences for sustainable products, and recycling) [34,36], while others found that one's PN could mediate the relationship between ESI and the intent to take green energy as well as the sustainable product preferences [37,38]. Besides, the results of recent research have shown that the VIP model could not only significantly predict the pro-environmental behaviors of employees in the organizational context [32], but also validly explain individuals' interests and adoption of green energy system [31]. Based on these researchers' findings, we proposed the VIP model could significantly explain TERB in China's context. Hence, this study proposed the following hypotheses:

Hypothesis $\mathbf{1}\left(\mathbf{H}_{\mathbf{1}}\right)$. Biospheric Values positively affect Environmental Self-Identity.

Hypothesis $\mathbf{2}\left(\mathbf{H}_{\mathbf{2}} \mathbf{)}\right.$. Environmental Self-Identity positively affects Personal Norm.

Hypothesis $3\left(\mathbf{H}_{3}\right)$. Personal Norm positively affects Tourists' Environmentally Responsible Behavior.

\subsection{The Extended Role of Environmental Self-efficacy in the VIP Model}

Self-efficacy was described by Bandura in 1977 as the self-belief of an individual's ability to perform a specific task [39], which could contribute to the adoption and performance of an individual's 
behavior [40]. Bandura pointed out that there is no general self-efficacy because one's self-efficacy is closely related to specific situations and widely varied in different areas [41]. Therefore, from the viewpoint of Bandura, this study defines the person's self-efficacy in the pro-environmental context as Environmental Self-Efficacy (ESE), which refers specifically to the belief that individuals have the ability to perform environmentally friendly behaviors to alleviate environmental problems [42].

Social cognitive theory holds that individual self-efficacy is mainly influenced by four kinds of information: (1) personal experience, such as the past experience of success or failure; (2) indirect experience (e.g., stemming from the experiences of others); (3) verbal persuasion (e.g., others' evaluation and persuasion, social media); and (4) emotional (physiological) arousal [43]. However, the impact of this information on self-efficacy is not automatic but requires a range of cognitive processes, such as selective attention, assessment, and judgment by individuals [44]. Compared with the information itself, the individual's cognitive processing about this information plays a more crucial role in the formation of self-efficacy [41]. Hence, when one shapes some kind of identity with himself/herself, he or she has a higher self-efficacy in this field. For example, corporate employees' creative self-identity can enhance their creative self-efficacy in ongoing work contexts [45]; a regular exerciser's self-identity can strengthen their self-regulatory efficacy in the exercise context [46]; and, a postgraduate's drinking self-identity can decrease their drink-refusal self-efficacy in the college [47]. Therefore, this study proposed that individuals' Environmental Self-Identity (ESI) would positively influence his or her ESE in a trip. Specifically, when someone regards himself/herself as an environmentally friendly person, he/she will pay more attention to the information related to ESE in the tourist destination, and thus he or she is more likely to form a higher ESE.

In addition, previous studies have shown that one's ESE can significantly and positively affect pro-environmental behaviors in different contexts, such as recycling [48], using public transport or cycling [49], and conserving water [50]. Furthermore, several empirical results indicated that ESE can validly contribute to different TERBs including engaging in recycling [51], going on environmental volunteer trips [9], and participating in campaigns and disseminating information for the sustainability of tourist destinations [10]. Hence, this study proposes the following hypotheses:

Hypothesis $\left.4 \mathbf{( H}_{\mathbf{4}}\right)$. Environmental Self-Identity positively affects Environmental Self-Efficacy.

Hypothesis $\left.\mathbf{5} \mathbf{( H}_{\mathbf{5}}\right)$. Environmental Self-Efficacy positively affects Tourists' Environmentally Responsible Behavior.

Based on the above literature review and the development of theoretical hypotheses, this study tested the proposed model, as seen in Figure 1.

\section{Methodology}

\subsection{Measurement Instruments}

In this study, the survey questionnaire was divided into two main parts. The first part included five latent variables: biospheric values, environmental self-identity, personal norm, environmental self-efficacy, and tourists' environmentally responsible behavior. All the measurement items (see Appendix A for details) were mainly adapted from previous environmentally responsible behavior studies as follows.

The 4-item biospheric values scale was developed by de Groot and Steg [33], which were validated in previous studies $[27,31,32]$. The 3 -item environmental self-identity scale was revised and derived from previous studies [52-54]. The 4-item personal norm scale was adapted from Steg and De Groot [55], which was used to examine environmentally friendly behavior of employees in the organizational context [32]. The 4-item environmental self-efficacy scale was adapted from Strzelecka, Woosnam, and Nisbett [9]. The 4-item tourists' environmentally responsible behavior scale was selected and modified based on Chiu, Lee, and Chen [12] and Pan and Liu [8]. All items of these scales were 
originally written in English and translated into Chinese by the researchers. In order to minimize translation bias and ensure conceptual equivalence of these items, one native English-speaker familiar with Chinese was asked to translate these Chinese items into English, and two academics specializing in tourism management were invited to evaluate the content validity of these items. All variables were measured on a 7-point Likert scale; BV ranged from "not very important" (1) to "very important" (7), while the other variables ranged from "strongly disagree" (1) to "strongly agree" (7).

The second part was the respondents' demographic variables, including gender, age, educational level, occupation, and monthly income.

\subsection{Data Collection}

Data were collected via the professional online survey platform: Questionnaire Star (https: //www.wjx.cn/), which is one of the largest online survey platforms in China. The platform has more than 2.6 million members and no less than 1 million active respondents every day that are willing to fill out questionnaires. The respondents were randomly selected through paid services in the platform's sample pool. Moreover, participants who visited natural destinations in the past month were eligible to participate in the survey. Additionally, we also randomly arranged 19 items of all latent variables to reduce mutual interference between different items of latent variables. Finally, a total of 435 sample data were collected within 2 weeks. The respondents had a relatively balanced male-to-female ratio $(50.8 \%$ vs. $49.2 \%)$ and $72.2 \%$ of respondents were between the ages of 21 and 40 . More details are shown in Table 1.

Table 1. The demographic results of the respondents.

\begin{tabular}{|c|c|c|}
\hline Variable \& Category & Frequency & Percentage $(\%)$ \\
\hline \multicolumn{3}{|l|}{ Gender } \\
\hline Male & 221 & 50.8 \\
\hline Female & 214 & 49.2 \\
\hline \multicolumn{3}{|l|}{ Age (Years old) } \\
\hline$\leq 20$ & 84 & 19.3 \\
\hline $21-30$ & 167 & 38.4 \\
\hline $31-40$ & 147 & 33.8 \\
\hline $41-50$ & 26 & 6 \\
\hline$\geq 51$ & 11 & 2.5 \\
\hline \multicolumn{3}{|l|}{ Monthly Income (RMB) } \\
\hline$\leq 2000$ & 40 & 9.2 \\
\hline $2001-4000$ & 67 & 15.4 \\
\hline $4001-6000$ & 94 & 21.6 \\
\hline $6001-8000$ & 93 & 21.4 \\
\hline $8001-10,000$ & 92 & 21.1 \\
\hline$\geq 10,001$ & 49 & 11.3 \\
\hline \multicolumn{3}{|l|}{ Education Level } \\
\hline High school or below & 13 & 3 \\
\hline College & 73 & 16.8 \\
\hline Bachelor & 317 & 72.9 \\
\hline Postgraduate & 32 & 7.4 \\
\hline \multicolumn{3}{|l|}{ Occupation } \\
\hline Government public official & 51 & 11.7 \\
\hline Corporate employee & 196 & 45.1 \\
\hline Teacher or Doctor & 81 & 18.6 \\
\hline Private owner & 47 & 10.8 \\
\hline Others & 60 & 13.8 \\
\hline
\end{tabular}




\subsection{Data Analysis}

First, the descriptive statistics (e.g., Skewness, Kurtosis, and Demographic profile of the sample) were analyzed using IBM SPSS Statistics 24.0 statistical software. Second, the reliability and validity of all variables were analyzed using the method of Covariance-Based Structural Equation Modeling (CB-SEM) [56], and IBM SPSS Amos 24.0 statistical software. Third, the Ordinary Least Squares (OLS) method was used by IBM SPSS Statistics 24.0 software in the linear regression analysis. Lastly, the mediation effect was analyzed by the bootstrap test method [57], using the Hayes PROCESS (version 3.3) macro in the IBM SPSS Statistics 24.0 software package.

\section{Results}

\subsection{Descriptive Statistical Analysis}

As shown in Table 1, among the 435 respondents, there were slightly more male (50.8\%) than female (49.2\%) participants. They were mainly distributed in two age groups: 21 to $30(38.4 \%)$ and 31 to $40(33.8 \%)$. Their monthly income followed an approximately normal distribution. Most of them $(80.3 \%)$ had bachelor or postgraduate educational experience. Nearly half $(45.1 \%)$ were employees of corporations. These demographic results were basically consistent with the sample pool of the specialized online survey platform, Questionnaire Star.

Table 2 shows that the values of skewness of Tourists' Environmentally Responsible Behavior, Personal Norm, Environmental Self-Efficacy, Environmental Self-Identity, and Biospheric Values were less than one, and the values of kurtosis for these variables were less than three. The coefficients of skewness and kurtosis indicated that the sample data were approximately in accordance with a normal distribution. Moreover, according to the suggestion of Curran, West, and Finch [58], the results of skewness and kurtosis also showed a normal distribution for all the items of these variables.

Table 2. The descriptive analysis of variables.

\begin{tabular}{ccccc}
\hline Variable \& Item & Mean & SD & Skewness & Kurtosis \\
\hline Biospheric Values (BV) & 5.83 & 0.78 & -0.77 & 0.73 \\
BV1 & 5.72 & 0.92 & -0.69 & 0.88 \\
BV2 & 5.89 & 0.88 & -0.71 & 0.74 \\
BV3 & 5.91 & 0.88 & -0.46 & -0.20 \\
BV4 & 5.80 & 1.01 & -1.07 & 2.12 \\
Environmental Self-Identity (ESI) & 5.63 & 0.94 & -0.85 & 0.95 \\
ESI1 & 5.70 & 0.96 & -1.01 & 1.90 \\
ESI2 & 5.62 & 1.05 & -0.58 & 0.19 \\
ESI3 & 5.57 & 1.04 & -0.65 & 0.39 \\
PNon1 & 5.73 & 0.75 & -0.53 & 0.85 \\
PN2 & 5.59 & 0.92 & -0.63 & 1.00 \\
PN3 & 5.76 & 0.87 & -0.31 & -0.15 \\
PN4 & 5.81 & 0.85 & -0.17 & -0.60 \\
ESE1 & 5.76 & 0.98 & -0.52 & -0.19 \\
ESE2 & 5.71 & 0.81 & -0.76 & 2.24 \\
ESE3 & 5.75 & 0.98 & -0.85 & 1.94 \\
ESE4 & 5.84 & 0.95 & -1.00 & 2.69 \\
Environment) & 5.43 & 1.12 & -0.56 & 0.33 \\
TERB1 & 5.82 & 0.91 & -0.65 & 1.20 \\
TERB2 & 5.07 & 1.12 & -0.90 & 0.89 \\
TERB3 & 5.08 & 1.15 & -0.80 & 0.90 \\
TERB4 & 5.10 & 1.21 & -0.73 & 0.56 \\
\hline
\end{tabular}




\subsection{Confirmatory Factor Analysis}

Confirmatory factor analysis (CFA) consisted of five latent variables and nineteen observed items. The results of the CFA (maximum likelihood method) were presented as follows: Chi-squares $=352.978$, $\mathrm{DF}=142$, Chi-squares $/ \mathrm{DF}=2.486, \mathrm{RMR}=0.042, \mathrm{RMSEA}=0.059, \mathrm{GFI}=0.918, \mathrm{CFI}=0.965, \mathrm{NFI}=0.944$, $\mathrm{IFI}=0.965$, and TLI $=0.958$. According to Hu and Bentley [59], the valid fit indices of the CFA were that Chi-squares/DF was less than 3, RMR was less than 0.05, RMSEA was less than 0.08, and GFI, CFI, NFI, IFI, and TLI were each more than 0.90 . All fit indexes indicated that the measurement model had an acceptable model fit.

As shown in Table 3, the Composite Reliability (CR) values ranged from 0.843 to 0.946 and had a larger than threshold (0.7) of reliability [60], which indicated that the reliability of all variables was good. Moreover, the convergent validity was assessed through the standardized factor loadings and the Average Variance Extracted (AVE). All standardized factor loadings of these items ranged from 0.661 to 0.923 and no less than the threshold (0.6) of acceptance [61], and the AVE values ranged from 0.573 to 0.815 and had greater than the least value (0.5) of limitation [62]. These two indexes showed that the convergent validity of all constructs was qualified.

Table 3. The analysis results of reliability and convergent validity.

\begin{tabular}{|c|c|c|c|c|}
\hline Variable \& Item & Std. Factor & SMC & CR & AVE \\
\hline Biospheric Values (BV) & & & 0.868 & 0.623 \\
\hline BV1 & 0.784 & 0.615 & & \\
\hline BV2 & 0.818 & 0.670 & & \\
\hline BV3 & 0.814 & 0.663 & & \\
\hline BV4 & 0.739 & 0.546 & & \\
\hline Environmental Self-Identity (ESI) & & & 0.915 & 0.781 \\
\hline ESI1 & 0.849 & 0.722 & & \\
\hline ESI2 & 0.902 & 0.813 & & \\
\hline $\mathrm{ESI} 3$ & 0.900 & 0.811 & & \\
\hline Personal Norm (PN) & & & 0.849 & 0.586 \\
\hline PN1 & 0.760 & 0.578 & & \\
\hline PN2 & 0.821 & 0.674 & & \\
\hline PN3 & 0.810 & 0.656 & & \\
\hline PN4 & 0.661 & 0.437 & & \\
\hline Environmental Self-Efficacy (ESE) & & & 0.843 & 0.573 \\
\hline ESE1 & 0.796 & 0.634 & & \\
\hline ESE2 & 0.783 & 0.613 & & \\
\hline ESE3 & 0.670 & 0.448 & & \\
\hline ESE4 & 0.773 & 0.598 & & \\
\hline $\begin{array}{l}\text { Tourists' Environmentally } \\
\text { Responsible Behavior (TERB) }\end{array}$ & & & 0.946 & 0.815 \\
\hline TERB1 & 0.899 & 0.809 & & \\
\hline TERB2 & 0.905 & 0.819 & & \\
\hline TERB3 & 0.923 & 0.853 & & \\
\hline TERB4 & 0.883 & 0.780 & & \\
\hline
\end{tabular}

Based on these results, the reliability and validity of all variables were acceptable, which meant that the sample data could be applied in the next analysis.

According to the suggestion of Fornell and Larcker [62], discriminant validity can be evaluated by comparing the square root of the AVE of all variables and the Pearson correlation coefficients between paired variables. If the square root of AVE is bigger than all the Pearson correlation coefficients, the discriminant validity is adequate. As shown in Table 4, the results showed that all the values of the Pearson correlation matrix were smaller than the square roots of AVE for each latent variable. 
Table 4. The results of discriminant validity analysis.

\begin{tabular}{cccccc}
\hline & BV & ESI & PN & ESE & TERB \\
\hline BV & 0.789 & & & & \\
ESI & 0.472 & 0.884 & & & \\
PN & 0.680 & 0.594 & 0.766 & & \\
ESE & 0.682 & 0.563 & 0.732 & 0.757 & \\
TERB & 0.482 & 0.398 & 0.542 & 0.572 & 0.903
\end{tabular}

Notes: BV = Biospheric Values, ESI = Environmental Self-Identity, PN = Personal Norm, ESE $=$ Environmental Self-Efficacy, TERB = Tourists' Environmentally Responsible Behavior. Diagonal values represent the square root of AVE for each variable; underneath the diagonal is the Pearson correlation matrix of all variables.

\subsection{Linear Regression Analysis}

This study used linear regression to assess the validity of $\mathrm{H}_{1}, \mathrm{H}_{2}, \mathrm{H}_{3}, \mathrm{H}_{4}$, and $\mathrm{H}_{5}$. The results are shown in Table 5. In Model 1, BV could significantly influence the $22.3 \%$ variance of ESI ( $\beta=0.569$, $p<0.001$ ), which suggested that $\mathrm{H}_{1}$ was supported by the data. In Model 2, ESI could significantly and positively affect $\mathrm{PN}(\beta=0.471, p<0.001)$, which meant $\mathrm{H}_{2}$ was supported. In Model 3, TERB was significantly influenced by PN $(\beta=0.813, p<0.001)$, which suggested $\mathrm{H}_{3}$ was supported. In Model 4 , ESI could significantly explain the $31.6 \%$ variance of ESE $(\beta=0.485, p<0.001)$, which showed $\mathrm{H}_{4}$ was supported. In Model 5 , the $36.0 \%$ variance of TERB $(F=121.347, p<0.001)$ was significantly influenced by ESE and PN. Specifically, the $6.6 \%$ variance of TERB was separately and significantly increased by $\operatorname{ESE}(\Delta \mathrm{F}=44.589, p<0.001)$, which indicated $\mathrm{H}_{5}$ was supported. Moreover, compared with the effect of PN on TERB $(b=0.266)$, the effect of ESE on TERB was more important $(b=0.377)$.

Table 5. The results of linear regression analysis.

\begin{tabular}{|c|c|c|c|c|c|c|c|c|c|c|c|c|}
\hline & \multicolumn{12}{|c|}{ Dependent Variables } \\
\hline & \multicolumn{4}{|c|}{ ESI (Model 1) } & \multicolumn{4}{|c|}{ PN (Model 2) } & \multicolumn{4}{|c|}{ TERB (Model 3) } \\
\hline & $\beta$ & $\mathrm{b}$ & $\mathrm{t}$ & $p$ & $\beta$ & $\mathrm{b}$ & $\mathrm{t}$ & $p$ & $\beta$ & $\mathrm{b}$ & $t$ & $p$ \\
\hline \multicolumn{13}{|l|}{ Predictors } \\
\hline BV & 0.569 & 0.472 & 11.153 & $* * *$ & & & & & & & & \\
\hline ESI & & & & & 0.471 & 0.594 & 15.375 & $* * *$ & & & & \\
\hline PN & & & & & & & & & 0.813 & 0.542 & 13.416 & $* * *$ \\
\hline \multicolumn{13}{|l|}{ Model } \\
\hline F & & 124.389 & & $* * *$ & & 236.385 & & $* * *$ & & 179.986 & & $* * *$ \\
\hline \multirow[t]{3}{*}{$\mathrm{R}^{2}$} & 0.223 & & & & 0.353 & & & & 0.294 & & & \\
\hline & \multicolumn{4}{|c|}{ ESE (Model 4) } & \multicolumn{4}{|c|}{ TERB (Model 5) } & & & & \\
\hline & $\beta$ & $\mathrm{b}$ & $\mathrm{t}$ & $p$ & $\beta$ & $\mathrm{b}$ & $t$ & $p$ & & & & \\
\hline \multicolumn{13}{|l|}{ Predictors } \\
\hline ESI & 0.485 & 0.563 & 14.158 & $* * *$ & & & & & & & & \\
\hline $\mathrm{PN}$ & & & & & 0.399 & 0.266 & 4.407 & $* * *$ & & & & \\
\hline ESE & & & & & 0.519 & 0.377 & 6.678 & $* * *$ & & & & \\
\hline \multicolumn{13}{|l|}{ Model } \\
\hline F & & 200.455 & & $* * *$ & & 121.347 & & $* * *$ & & & & \\
\hline $\mathrm{R}^{2}$ & 0.316 & & & & 0.360 & & & & & & & \\
\hline$\Delta \mathrm{F}$ & & & & & & 44.589 & & $* * *$ & & & & \\
\hline$\Delta \mathrm{R}^{2}$ & & & & & 0.066 & & & & & & & \\
\hline
\end{tabular}

Notes: BV = Biospheric Values, ESI = Environmental Self-Identity, ESE = Environmental Self-Efficacy, PN = Personal Norm, TERB = Tourists' Environmentally Responsible Behavior, $\beta=$ Unstandardized Regression Coefficients, $b=$ Standardized Regression Coefficients, “*** represents $p<0.01$, “****" represents $p<0.001$.

\subsection{Mediation Effect Analysis}

In order to further analyze the formed mechanism of TERB, the mediation effects of ESI, ESE, and PN in the relationship between BV and TERB were examined, and the method of percentile bootstrap confidence interval was applied [63]. Specifically, 5000 bootstrap samples and $95 \%$ confidence interval were set in PROCESS 3.3, and Model 6 and Model 81 tested the original and extended VIP 
models, respectively. The results are detailed in Table 6. In Model 6, the indirect effect of BV on TERB was significant $(\mathrm{LLCI}=0.048, \mathrm{ULCI}=0.129$ ), which indicated the original VIP model was valid in the Chinese context. In Model 81, two indirect effects of BV on TERB were significant. The mediation effect of Ind1 was 0.051 (LLCI $=0.015$, ULCI $=0.094)$ and that of Ind2 was $0.069(\mathrm{LLCI}=0.034, \mathrm{ULCI}=0.107)$, which indicated the extended VIP model was supported by the data. Moreover, the direct effect of BV on TERB was not significant $(\mathrm{LLCI}=-0.027$, ULCI $=0.291$ ), which suggested the two indirect paths played a full mediational role in the relationship between BV and TERB. Furthermore, although the effect of Ind1 was less than the effect of Ind2, the effect of "Ind1 minus Ind2" was not significant $(\mathrm{LLCI}=-0.079$, ULCI $=0.046)$, which indicated that Ind1 and Ind2 played the same mediated role in the relationship between $\mathrm{BV}$ and TERB.

Table 6. Total, direct, and indirect effect analysis results.

\begin{tabular}{|c|c|c|c|c|c|c|}
\hline Model & Path & Effect & Std. Error & t-Value & LLCI & ULCI \\
\hline \multirow{6}{*}{6} & The total effect of BV on TERB & & & & & \\
\hline & $\mathrm{BV} \rightarrow \mathrm{TERB}$ & 0.690 & 0.060 & 11.437 & 0.571 & 0.808 \\
\hline & The direct effect of BV on TERB & & & & & \\
\hline & $\mathrm{BV} \rightarrow \mathrm{TERB}$ & 0.284 & 0.078 & 3.647 & 0.131 & 0.437 \\
\hline & The indirect effect of BV on TERB & & & & & \\
\hline & $\mathrm{BV} \rightarrow \mathrm{ESI} \rightarrow \mathrm{PN} \rightarrow \mathrm{TERB}$ & 0.083 & 0.021 & 3.952 & 0.048 & 0.129 \\
\hline \multirow{8}{*}{81} & The total effect of BV on TERB & & & & & \\
\hline & $\mathrm{BV} \rightarrow \mathrm{TERB}$ & 0.690 & 0.060 & 11.437 & 0.571 & 0.808 \\
\hline & The direct effect of BV on TERB & & & & & \\
\hline & $\mathrm{BV} \rightarrow \mathrm{TERB}$ & 0.132 & 0.081 & 1.635 & -0.027 & 0.291 \\
\hline & The indirect effects of BV on TERB & & & & & \\
\hline & Ind1: BV $\rightarrow$ ESI $\rightarrow$ PN $\rightarrow$ TERB & 0.051 & 0.020 & 2.548 & 0.015 & 0.094 \\
\hline & Ind2: $\mathrm{BV} \rightarrow$ ESI $\rightarrow$ ESE $\rightarrow$ TERB & 0.069 & 0.019 & 3.714 & 0.034 & 0.107 \\
\hline & Ind1 minus Ind 2 & -0.018 & 0.031 & -0.595 & -0.079 & 0.046 \\
\hline
\end{tabular}

Notes: BV = Biospheric Values, ESI = Environmental Self-Identity, ESE = Environmental Self-Efficacy, PN = Personal Norm, TERB = Tourists' Environmentally Responsible Behavior.

\section{Discussion and Conclusions}

This study proposed an extended VIP model based on the original VIP model and self-efficacy theory, and systematically explored the relationship between BV, ESI, ESE, PN, and TERB. Through empirical testing, all the hypotheses of the proposed model were supported by the sample data. Firstly, $\mathrm{H}_{1}$ indicated that BV had a positive relationship with ESI, which meant that the higher tourists' BV, the stronger their ESI in the tourist destinations. This is consistent with the findings of van der Werff, Steg, and Keizer [34,54], who confirmed that one's BV would significantly strengthen his/her ESI. Secondly, $\mathrm{H}_{2}$ showed that tourists' ESI was positively related to $\mathrm{PN}$, which indicated that the stronger one's ESI in a trip, the more strongly a visitor had PN. This is in line with the findings of Barbarossa, De Pelsmacker and Moons [38], who stated that one's ESI can enhance the feeling of moral obligation to act in an environmentally friendly manner. Thirdly, $\mathrm{H}_{3}$ revealed that tourists who have the feeling of moral obligation to perform environmentally responsible behavior are more willing to fulfill TERB, which is consistent with the research of Han [27] and Han and Hyun [21]. Fourthly, $\mathrm{H}_{4}$ illustrated that one's ESI can strengthen his/her ESE in the tourism context, which empirically validates a number of previous studies in different contexts, such as Foster, Yeung, and Neighbors [47] and Tierney and Farmer [45]. Finally, $\mathrm{H}_{5}$ demonstrated that tourists who are confident in their abilities to protect the environment would be more likely to carry out TERB. This is consistent with the findings of Strzelecka, Woosnam, and Nisbett [9] and Shahzalal and Font [10].

In summary, we come to the following three conclusions. First, the VIP model can effectively predict TERB in China. Second, ESE can significantly increase the predictability of the VIP model. Third, the indirect path of "BV $\rightarrow$ ESI $\rightarrow$ ESE $\rightarrow$ TERB" can deepen the understanding of the formation of TERB for the researchers. 


\section{Contributions, Implications, and Future Research Directions}

The theoretical contributions of this study can be divided into two parts. For one thing, the validity of the original VIP model was empirically tested in China. Specifically, we examined the extent of generally environmental considerations (including biospheric values and environmental self-identity) and how to predict tourists' environmentally responsible behavior in a trip. Previous studies of the VIP model on pro-environmental behavior were conducted mainly in the home and organizational contexts [31,32]. The findings of this study are consistent with those studies, and further enriches the applicable situation of the VIP model. For another, the predictive power of VIP on TERB was enhanced by the extension of Environmental Self-Efficacy (ESE). In the extended VIP model, ESE can significantly and positively affect TERB, which once again confirms the findings of previous researchers in the sustainable tourism field $[9,10,25]$. Compared with PN, ESE has a greater impact on TERB. Moreover, the mediating effect of "BV $\rightarrow$ ESI $\rightarrow$ ESE $\rightarrow$ TERB" is verified for the first time, which has the same important mediating role as the existing indirect path (i.e., $\mathrm{BV} \rightarrow \mathrm{ESI} \rightarrow \mathrm{PN} \rightarrow \mathrm{TERB}$ ). The finding is a prominent contribution to this study.

The managerial implications for the practitioners, including government authorities and tourist destination managers, are as follows: First of all, we have proved that ESE positively affects TERB. Therefore, if practitioners would like to prompt TERB in tourist destinations, they need to strengthen tourists' ESE. According to social cognitive theory [43], the managers can shape tourists' sense of efficacy for eco-friendly behavior through the persuasion of media information. Secondly, this study found TERB was significantly influenced by tourists' PN. As a result, managers should effectively activate tourists' PN by the diverse channels based on norm activation theory [26]. Finally, if government authorities would like to motivate TERB, they should enhance tourists' BV and ESI, since the results showed that BV and ESI had an indirect effect on TERB through ESE or PN. Moreover, BV and ESI, as individuals' general environmental considerations [31,32], can also promote the spillover effects of environmentally responsible behavior.

In addition, there are some research limitations in this study, and future research needs to be improved. First, the cross-sectional design was adopted in this study, which may make the causal inference between variables less reliable than that of a longitudinal design. Future studies should adopt a longitudinal or experimental design to verify the causal relationship of the original and extended VIP model. Second, although the data collection was completed by a professional online survey platform, it was still a convenient sampling. Future research should optimize sampling design to collect data from multiple regions to further enhance the external validity of the conclusions. Finally, this study only validated and extended the mechanisms of the VIP model on specific TERB, but where the theoretical boundaries of these mechanisms are, and which variables will increase the explanatory power of these mechanisms, remain to be determined. Thus, future research should introduce moderated variables, such as behavioral cost [64], to explore the theoretical boundaries of the original and extended VIP model.

Author Contributions: Y.X. mainly wrote the literature review and hypotheses, proposed the theoretical framework, developed the measurement instruments, and performed the statistical analysis. X.W. contributed to the introduction, research design, and data collection. S.-C.C. discussed the results and concluded the contributions and implications. All authors supported and were responsible for this paper.

Funding: This research was funded by the Ph.D. project of Xuzhou Vocational College of Industrial Technology (XGY2017EB02), the general project of philosophy and social science research of Jiangsu Education Department (2016SJB630088), and the key funding project of Jiangsu Province Education Science "Thirteen-Five" Planning (B-a/2016/03/15).

Conflicts of Interest: The authors declare no conflict of interest. 


\section{Appendix A}

\begin{tabular}{l}
\hline Variable \& Item \\
\hline Biospheric Values \\
\hline Preventing pollution: protecting natural resources \\
Respecting the earth: harmony with other species \\
Unity with nature: fitting into nature \\
Protecting the environment: preserving nature \\
\hline Environmental Self-Identity \\
\hline Acting in an environmentally friendly manner is an important part of who I am \\
I am the type of person who acts in an environmentally friendly manner \\
I see myself as an environmentally friendly person \\
\hline Personal Norm \\
\hline I feel guilty if I do not act pro-environmentally in travel \\
I feel morally obliged to act pro-environmentally in travel \\
I feel proud when I act pro-environmentally in travel \\
I would violate my principles if I would not act pro-environmentally in travel \\
\hline Environmental Self-Efficacy \\
\hline I am capable of making a positive impact on the environment \\
I am able to help take care of nature \\
I believe I can contribute to solutions to environmental problems by my actions \\
Compared to other people, I think I can make a positive impact on the environment \\
\hline Tourists' Environmentally Responsible Behavior \\
\hline I will not walk on the grass, or wreck and climb trees \\
I will not throw my trash on the ground or into a pool or river \\
I will not paint or scratch historic and cultural buildings and statues \\
I will comply with the rules and regulations of destinations, and if I see my companions doing bad things to \\
the destination, I will persuade them to stop \\
\hline
\end{tabular}

\section{References}

1. The Basic Situation of the Chinese Tourism Market in 2018. Available online: http://zwgk.mct.gov.cn/auto255/ 201902/t20190212_837271.html (accessed on 19 May 2019).

2. Lim, C.; McAleer, M. Ecologically sustainable tourism management. Environ. Model. Softw. 2005, 20, 1431-1438. [CrossRef]

3. Krider, R.E.; Arguello, A.; Campbell, C.; Mora, J.-D. Trait and image interaction: In Ecotourism Preference. Ann. Tour. Res. 2010, 37, 779-801. [CrossRef]

4. Moeller, T.; Dolnicar, S.; Leisch, F. The sustainability-profitability trade-off in tourism: Can it be overcome? J. Sustain. Tour. 2011, 19, 155-169. [CrossRef]

5. Dolnicar, S.; Leisch, F. Selective marketing for environmentally sustainable tourism. Tour. Manag. 2008, 29, 672-680. [CrossRef]

6. Weaver, D.B.; Lawton, L.J. Visitor Loyalty at a Private South Carolina Protected Area. J. Travel Res. 2010, 50, 335-346. [CrossRef]

7. $\mathrm{Hu}, \mathrm{H} . ;$ Zhang, J.; Wang, C.; Yu, P.; Chu, G. What influences tourists' intention to participate in the Zero Litter Initiative in mountainous tourism areas: A case study of Huangshan National Park, China. Sci. Total Environ. 2019, 657, 1127-1137. [CrossRef] [PubMed]

8. Pan, Y.; Liu, J.-G. Antecedents for College Students' Environmentally Responsible Behavior: Implications for Collective Impact and Sustainable Tourism. Sustainability 2018, 10, 2024. [CrossRef]

9. Strzelecka, M.; Woosnam, K.M.; Nisbett, G.S. Self-efficacy mechanism at work: The context of environmental volunteer travel. J. Sustain. Tour. 2018, 26, 2002-2020. [CrossRef] 
10. Shahzalal, M.; Font, X. Influencing altruistic tourist behaviour: Persuasive communication to affect attitudes and self-efficacy beliefs. Int. J. Tour. Res. 2018, 20, 326-334. [CrossRef]

11. Lee, T.H.; Jan, F.-H.; Yang, C.-C. Conceptualizing and measuring environmentally responsible behaviors from the perspective of community-based tourists. Tour. Manag. 2013, 36, 454-468. [CrossRef]

12. Chiu, Y.-T.H.; Lee, W.-I.; Chen, T.-H. Environmentally responsible behavior in ecotourism: Antecedents and implications. Tour. Manag. 2014, 40, 321-329. [CrossRef]

13. Hedlund, T.; Marell, A.; Gärling, T. The mediating effect of value orientation on the relationship between socio-demographic factors and environmental concern in Swedish tourists' vacation choices. J. Ecotour. 2012, 11, 16-33. [CrossRef]

14. Dolnicar, S. Insights into Sustainable Tourists in Austria: A Data-based A Priori Segmentation Approach. J. Sustain. Tour. 2004, 12, 209-218. [CrossRef]

15. Ateljevic, I.; Doorne, S. 'Staying Within the Fence': Lifestyle Entrepreneurship in Tourism. J. Sustain. Tour. 2000, 8, 378-392. [CrossRef]

16. Han, H.; Hyun, S.S. College youth travelers' eco-purchase behavior and recycling activity while traveling: An examination of gender difference. J. Travel Tour. Mark. 2017, 35, 740-754. [CrossRef]

17. He, X.; Hu, D.; Swanson, S.R.; Su, L.; Chen, X. Destination perceptions, relationship quality, and tourist environmentally responsible behavior. Tour. Manag. Perspect. 2018, 28, 93-104. [CrossRef]

18. Lee, H.Y.; Bonn, M.A.; Reid, E.L.; Kim, W.G. Differences in tourist ethical judgment and responsible tourism intention: An ethical scenario approach. Tour. Manag. 2017, 60, 298-307. [CrossRef]

19. Cheng, T.-M.; Wu, H.C. How do environmental knowledge, environmental sensitivity, and place attachment affect environmentally responsible behavior? An integrated approach for sustainable island tourism. J. Sustain. Tour. 2014, 23, 557-576. [CrossRef]

20. Zhao, M.; Dong, S.; Wu, H.C.; Li, Y.; Su, T.; Xia, B.; Zheng, J.; Guo, X. Key impact factors of visitors' environmentally responsible behaviour: Personality traits or interpretive services? A case study of Beijing's Yuyuantan Urban Park, China. Asia Pac. J. Tour. Res. 2018, 23, 792-805. [CrossRef]

21. Han, H.; Hyun, S.S. Drivers of customer decision to visit an environmentally responsible museum: Merging the theory of planned behavior and norm activation theory. J. Travel Tour. Mark. 2017, 34, 1155-1168. [CrossRef]

22. Han, H.; Hwang, J. Norm-based loyalty model (NLM): Investigating delegates' loyalty formation for environmentally responsible conventions. Int. J. Hosp. Manag. 2015, 46, 1-14. [CrossRef]

23. Brown, T.J. Antecedents of culturally significant tourist behavior. Ann. Tour. Res. 1999, 26, 676-700. [CrossRef]

24. Aise KyoungJin, K.; Airey, D.; Szivas, E. The Multiple Assessment of Interpretation Effectiveness: Promoting Visitors' Environmental Attitudes and Behavior. J. Travel Res. 2010, 50, 321-334. [CrossRef]

25. Lee, S.J.; Lina Kim, H. Roles of perceived behavioral control and self-efficacy to volunteer tourists' intended participation via theory of planned behavior. Int. J. Tour. Res. 2018, 20, 182-190. [CrossRef]

26. Qiao, G.; Gao, J. Chinese Tourists' Perceptions of Climate Change and Mitigation Behavior: An Application of Norm Activation Theory. Sustainability 2017, 9, 1322. [CrossRef]

27. Han, H. Travelers' pro-environmental behavior in a green lodging context: Converging value-belief-norm theory and the theory of planned behavior. Tour. Manag. 2015, 47, 164-177. [CrossRef]

28. Lee, T.H.; Jan, F.-H. Ecotourism Behavior of Nature-Based Tourists: An Integrative Framework. J. Travel Res. 2017, 57, 792-810. [CrossRef]

29. Ajzen, I. The theory of planned behavior. Organ. Behav. Hum. Decis. Process. 1991, 50, 179-211. [CrossRef]

30. Stern, P.C. New Environmental Theories: Toward a Coherent Theory of Environmentally Significant Behavior. J. Soc. Issues 2000, 56, 407-424. [CrossRef]

31. Van der Werff, E.; Steg, L. The psychology of participation and interest in smart energy systems: Comparing the value-belief-norm theory and the value-identity-personal norm model. Energy Res. Soc. Sci. 2016, 22, 107-114. [CrossRef]

32. Ruepert, A.; Keizer, K.; Steg, L.; Maricchiolo, F.; Carrus, G.; Dumitru, A.; García Mira, R.; Stancu, A.; Moza, D. Environmental considerations in the organizational context: A pathway to pro-environmental behaviour at work. Energy Res. Soc. Sci. 2016, 17, 59-70. [CrossRef] 
33. De Groot, J.I.M.; Steg, L. Value orientations to explain beliefs related to environmental significant behavior: How to measure egoistic, altruistic, and biospheric value orientations. Environ. Behav. 2008, 40, 330-354. [CrossRef]

34. Van der Werff, E.; Steg, L.; Keizer, K. The value of environmental self-identity: The relationship between biospheric values, environmental self-identity and environmental preferences, intentions and behaviour. J. Environ. Psychol. 2013, 34, 55-63. [CrossRef]

35. Harland, P.; Staats, H.; Wilke, H.A.M. Explaining proenvironmental intention and behavior by personal norms and the theory of planned behavior. J. Appl. Soc. Psychol. 1999, 29, 2505-2528. [CrossRef]

36. Gatersleben, B.; Murtagh, N.; Abrahamse, W. Values, identity and pro-environmental behaviour. Contemp. Soc. Sci. 2014, 9, 374-392. [CrossRef]

37. Van der Werff, E.; Steg, L.; Keizer, K. It is a moral issue: The relationship between environmental self-identity, obligation-based intrinsic motivation and pro-environmental behaviour. Glob. Environ. Chang. 2013, 23, 1258-1265. [CrossRef]

38. Barbarossa, C.; De Pelsmacker, P.; Moons, I. Personal Values, Green Self-identity and Electric Car Adoption. Ecol. Econ. 2017, 140, 190-200. [CrossRef]

39. Bandura, A. Self-efficacy: Toward a Unifying Theory of Behavioral Change. Psychol. Rev. 1977, 84, $191-215$. [CrossRef]

40. Bandura, A. Environmental sustainability by sociocognitive deceleration of population growth. In Psychology of Sustainable Development; Kluwer Academic Publishers: Dordrecht, The Netherlands, 2002; pp. 209-238.

41. Bandura, A. Self-Efficacy: The Exercise of Control; Freeman: New York, NY, USA, 1997.

42. Huang, H. Media use, environmental beliefs, self-efficacy, and pro-environmental behavior. J. Bus. Res. 2016, 69, 2206-2212. [CrossRef]

43. Bandura, A. Self-efficacy mechanism in human agency. Am. Psychol. 1982, 37, 122-147. [CrossRef]

44. Bandura, A. Self-efficacy mechanism in psychobiologic functioning. In Self-Efficacy: Thought Control of Action; Hemisphere Publishing Corp: Washington, DC, USA, 1992; pp. 355-394.

45. Tierney, P.; Farmer, S.M. Creative Self-Efficacy Development and Creative Performance over Time. J. Appl. Psychol. 2011, 96, 277-293. [CrossRef] [PubMed]

46. Strachan, S.M.; Brawley, L.R.; Spink, K.S.; Sweet, S.N.; Perras, M.G.M. Self-regulatory efficacy's role in the relationship between exercise identity and perceptions of and actual exercise behaviour. Psychol. Sport Exerc. 2015, 18, 53-59. [CrossRef]

47. Foster, D.W.; Yeung, N.C.Y.; Neighbors, C. I think I can't: Drink refusal self-efficacy as a mediator of the relationship between self-reported drinking identity and alcohol use. Addict. Behav. 2014, 39, 461-468. [CrossRef] [PubMed]

48. Tabernero, C.; Hernandez, B. Self-efficacy and intrinsic motivation guiding environmental behavior. Environ. Behav. 2011, 43, 658-675. [CrossRef]

49. Chen, M.-F. Self-efficacy or collective efficacy within the cognitive theory of stress model: Which more effectively explains people's self-reported proenvironmental behavior? J. Environ. Psychol. 2015, 42, 66-75. [CrossRef]

50. Lauren, N.; Fielding, K.S.; Smith, L.; Louis, W.R. You did, so you can and you will: Self-efficacy as a mediator of spillover from easy to more difficult pro-environmental behaviour. J. Environ. Psychol. 2016, 48, 191-199. [CrossRef]

51. Grazzini, L.; Rodrigo, P.; Aiello, G.; Viglia, G. Loss or gain? The role of message framing in hotel guests' recycling behaviour. J. Sustain. Tour. 2018, 26, 1944-1966. [CrossRef]

52. Terry, D.J.; Hogg, M.A.; White, K.M. The theory of planned behaviour: Self-identity, social identity and group norms. Br. J. Soc. Psychol. 1999, 38, 225-244. [CrossRef]

53. Fielding, K.S.; McDonald, R.; Louis, W.R. Theory of planned behaviour, identity and intentions to engage in environmental activism. J. Environ. Psychol. 2008, 28, 318-326. [CrossRef]

54. Van der Werff, E.; Steg, L.; Keizer, K. I Am What I Am, by Looking Past the Present: The Influence of Biospheric Values and Past Behavior on Environmental Self-Identity. Environ. Behav. 2014, 46, 626-657. [CrossRef]

55. Steg, L.; De Groot, J.I.M. Explaining prosocial intentions: Testing causal relationships in the norm activation model. Br. J. Soc. Psychol. 2010, 49, 725-743. [CrossRef] [PubMed] 
56. Jöreskog, K.G. Structural analysis of covariance and correlation matrices. Psychometrika 1978, 43, 443-477. [CrossRef]

57. Zhao, X.; Lynch, J.G.; Chen, Q. Reconsidering Baron and Kenny: Myths and Truths about Mediation Analysis. J. Consum. Res. 2010, 37, 197-206. [CrossRef]

58. Curran, P.J.; West, S.G.; Finch, J.F. The robustness of test statistics to nonnormality and specification error in confirmatory factor analysis. Psychol. Methods 1996, 1, 16-29. [CrossRef]

59. Hu, L.T.; Bentler, P.M. Cutoff criteria for fit indexes in covariance structure analysis: Conventional criteria versus new alternatives. Struct. Equ. Model. Multidiscip. J. 1999, 6, 1-55. [CrossRef]

60. Bagozzi, R.P.; Yi, Y. On the evaluation of structural equation models. J. Acad. Mark. Sci. 1988, 16, 74-94. [CrossRef]

61. Chin, W.W.; Peterson, R.A.; Brown, S.P. Structural Equation Modeling in Marketing: Some Practical Reminders. J. Mark. Theory Pract. 2008, 16, 287-298. [CrossRef]

62. Fornell, C.; Larcker, D.F. Evaluating Structural Equation Models with Unobservable Variables and Measurement Error. J. Mark. Res. 1981, 18, 39-50. [CrossRef]

63. Preacher, K.J.; Hayes, A.F. Asymptotic and resampling strategies for assessing and comparing indirect effects in multiple mediator models. Behav. Res. Methods 2008, 40, 879-891. [CrossRef]

64. He, X.; Zhan, W. How to activate moral norm to adopt electric vehicles in China? An empirical study based on extended norm activation theory. J. Clean. Prod. 2017, 172, 3546-3556. [CrossRef]

(C) 2019 by the authors. Licensee MDPI, Basel, Switzerland. This article is an open access article distributed under the terms and conditions of the Creative Commons Attribution (CC BY) license (http://creativecommons.org/licenses/by/4.0/). 